\title{
Severe Intracranial Involvement in Giant Cell Arteritis: 5 Cases and Literature Review
}

\author{
Roaa S. Alsolaimani, Sankalp V. Bhavsar, Nader A. Khalidi, Christian Pagnoux, \\ Jennifer L. Mandzia, Keng Yeow Tay, and Lillian J. Barra
}

\begin{abstract}
Objective. Involvement of intracranial arteries in giant cell arteritis (GCA) is rare. We describe the neurologic complications of intracranial GCA (IC GCA) and available treatment options.

Methods. We describe 5 IC GCA cases from 3 Canadian vasculitis centers and review the literature. We searched English-language publications reporting similar patients meeting American College of Rheumatology (ACR) criteria for GCA and having intracranial artery involvement diagnosed by autopsy, magnetic resonance angiography, computed tomography angiography, or conventional angiography.

Results. All 5 cases of IC GCA met ACR criteria for GCA; 4 cases had a temporal artery biopsy that was consistent with GCA. All cases experienced cerebrovascular accident(s). Arteritis involved the following vessels: intracranial internal carotid $(n=1)$, vertebrobasilar arteries $(n=1)$, or both $(n=3)$. All cases received aspirin and oral prednisone (preceded by intravenous methylprednisone in 3 cases), combined with an immunosuppressant in 4 cases. All patients survived; 2 had complete neurological recovery, 3 had residual neurologic sequelae. The literature review included 42 cases from 28 publications. The clinical features of the reported cases were similar to those of our 5 cases. However, mortality was $100 \%$ in untreated cases $(n=2), 58 \%$ in those treated with corticosteroid alone $(\mathrm{n}=31)$, and $40 \%$ in those treated with corticosteroid and an immunosuppressant $(\mathrm{n}=10)$.

Conclusion. IC GCA appears to be associated with neurologic complications and mortality. In some cases corticosteroid alone was not sufficient to prevent neurologic complications. The role of additional immunosuppressive agents needs further investigation. (First Release January 15 2016; J Rheumatol 2016;43:648-56; doi:10.3899/jrheum.150143)
\end{abstract}

Key Indexing Terms:

GIANT CELL ARTERITIS

STROKE

CRANIAL ARTERY

Giant cell arteritis (GCA) is large-vessel vasculitis affecting individuals over age 50 years, with a prevalence of about 3 in $10,000^{1}$. Complications of GCA can be serious, including blindness, stroke, and aortic dissection. Cerebrovascular accidents (CVA) occur in $4 \%$ to $6 \%$ of patients with $\mathrm{GCA}^{2}$. Despite being uncommon, CVA is reported as the leading cause of mortality in $\mathrm{GCA}^{3,4}$. The causes of CVA in GCA are

From the Division of Rheumatology, Western University, London; Division of Rheumatology, McMaster University, Hamilton; Division of Rheumatology, Mount Sinai Hospital, University of Toronto, Toronto; Department of Clinical Neurological Sciences and Division of Radiology, Western University, London, Ontario, Canada; and Department of Medicine, King Abdul-Aziz University Hospital, Jeddah, Saudi Arabia.

R.S. Alsolaimani, MD, Division of Rheumatology, Western University, Department of Medicine, King Abdul-Aziz University Hospital; S.V. Bhavsar, MD; N.A. Khalidi, MD, FRCPC, FACP, FACR, Division of Rheumatology, McMaster University; C. Pagnoux, MBI, MPH, PhD,

Division of Rheumatology, Mount Sinai Hospital, University of Toronto; J.L. Mandzia, MD, PhD, FRCPC, Department of Clinical Neurological Sciences, Western University; K.Y. Tay, MBBS, BSc(Med), FRCR, Division of Radiology, Western University; L.J. Barra, MD, MPH, FRCPC,

Division of Rheumatology, Western University.

Address correspondence to Dr. L.J. Barra, Division of Rheumatology, Western University, 268 Grosvenor St., London, Ontario N6A 4V2, Canada.E-mail:lbarra2@uwo.ca

Accepted for publication August 28, 2015. multifactorial and include hypercoagulability and accelerated atherosclerosis from a chronic proinflammatory state, treatment complications from longterm high-dose corticosteroids, and direct damage to blood vessels from arteritis. GCA is usually limited to extracranial vessels including the carotid artery, which can contribute to risk of stroke. It has been suggested that the inflammation in GCA usually involves the elastic tissue in the artery wall, and because the intradural portions of the artery have little or no elastic tissue, they tend to be spared ${ }^{4}$. However, cases of intracranial portions of the internal carotid and vertebral artery have been reported $^{4,5,6,7,8}$. Although involvement of intracranial arteries is rare in GCA, it can lead to severe neurologic complications, such as multiple territory CVA, multiinfarct dementia, and death.

We describe 5 new cases of intracranial GCA (IC GCA) and review 42 cases in the literature to detail presentation, diagnosis, treatment, and outcomes of this rare association.

\section{MATERIALS AND METHODS}

Case series. We reviewed medical charts of 5 patients with IC GCA in 3 Canadian vasculitis specialty centers (CanVasc). All cases were diagnosed with GCA by the treating physician and they met the American College of Rheumatology (ACR) classification criteria for $\mathrm{GCA}^{9}$. Temporal artery

Personal non-commercial use only. The Journal of Rheumatology Copyright ( $)$ 2016. All rights reserved. 
biopsy was performed in all cases within 1 to 2 weeks of presentation, except Case 4 (biopsy was performed a month later). They presented with CVA and had evidence of intracranial vasculitis on magnetic resonance angiography (MRA), computed tomographic angiography (CTA), or conventional angiography. Data regarding age, sex, GCA and neurologic symptoms, timing of neurologic symptoms, laboratory tests [erythrocyte sedimentation rate (ESR) and C-reactive protein (CRP), investigation for thrombophilia and vasculitis], imaging studies, treatments, and outcomes were collected from medical records. Research Ethics Board Approval from participating institutions was obtained.

Systematic literature review. We searched the following databases: PubMed, Embase (1950-December 2012), and the Cochrane library (up to December 2012). Abstracts from ACR (2009-2012) and European League Against Rheumatism (EULAR) annual meetings were searched (2009-2012). Our literature search combined the terms "giant cell arteritis," "temporal arteritis," "stroke," and "multi-infarct dementia" (for full search strategy see Appendix 1). A hand search of references in relevant articles was also conducted to identify additional cases.

Publication selection. Two authors (RA and LB) independently conducted the literature search and screened citations. Citations were first screened by title and abstract to retrieve relevant articles. The retrieved articles were then reviewed in full, applying the following inclusion criteria: GCA diagnosed by treating physician based on clinical presentation, temporal artery biopsy, inflammatory markers, and/or imaging; ACR classification criteria for GCA with at least 3 out of 5 criteria met or a temporal artery biopsy consistent with GCA; CVA diagnosed by treating physician based on clinical symptoms and imaging; and involvement of the intracranial portions (within the skull) of the internal carotid artery (ICA) and its branches, vertebral artery, or basilar artery. Intracranial involvement for ICA and vertebral artery was classified into: (1) extradural: intracranial segment of vessel prior to dural perforation; and (2) intradural: intracranial segment after piercing the dura ${ }^{4}$. This distinction was included based on reports that suggested that intradural involvement was exceedingly rare $^{4}$ and may be associated with worse outcomes. Patients with only extracranial involvement were excluded. Vessel involvement had to be determined by autopsy (histologic examination), MRA, CTA, or conventional angiography. Diagnosis made by duplex ultrasonography was excluded. Articles in a language other than English were excluded.

Data extraction. From the selected articles we extracted the publication details, followup times, clinical presentation, ESR, biopsy and imaging investigations, treatment, outcomes, and, if applicable, autopsy reports. We did not collect CRP values because these were not reported in the majority of papers. Definitions of complete versus partial recovery were heterogeneous across studies. We defined "no residual neurologic symptoms" based on physician opinion as complete recovery and "any residual neurologic symptoms" as partial recovery.

\section{RESULTS}

Case series. The characteristics of our 5 cases with IC GCA are summarized in Table 1 . All cases had at least 1 risk factor for atherosclerosis. All had a temporal artery biopsy that was consistent with GCA, except Case 5, who had a normal temporal artery on biopsy. Hypercoagulable state and systemic vasculitis were ruled out in all cases. All were treated with corticosteroids and aspirin (ASA; 3 at diagnosis and 2 after CVA) and 4/5 with additional immunosuppressant(s). In applicable cases, the management of cardiovascular risk factors was optimized. Classic GCA symptoms improved within $48 \mathrm{~h}$ of starting treatment. All patients survived with no relapses requiring increased corticosteroids or the additional immunosuppressive agents during their followup. Two of the 5 had complete neurologic recovery and the remaining had mild impairments; improvement in neurologic symptoms occurred slowly over the course of followup. Case 1. A 75-year-old man presented with headaches and painless vision loss. He had evidence of arteritic ischemic optic neuropathy in the left eye. Prednisone $80 \mathrm{mg}$ was initiated. Two weeks later, he presented with disorientation, receptive aphasia, behavior changes, acute apraxia, and right-side weakness. MRA of the head showed severe narrowing of the left ICA and irregularities in both posterior cerebral arteries (Figure 1A). He was given ASA and high-dose prednisone $80 \mathrm{mg}$ was continued. A month later, he presented with worsening confusion and personality changes. MRA of the head showed 2 new infarcts within the left middle cerebral artery (MCA) territory in the left frontal lobe. CTA of the head showed progressive narrowing of the left ICA lesion to the point of near occlusion distally. $\mathrm{He}$
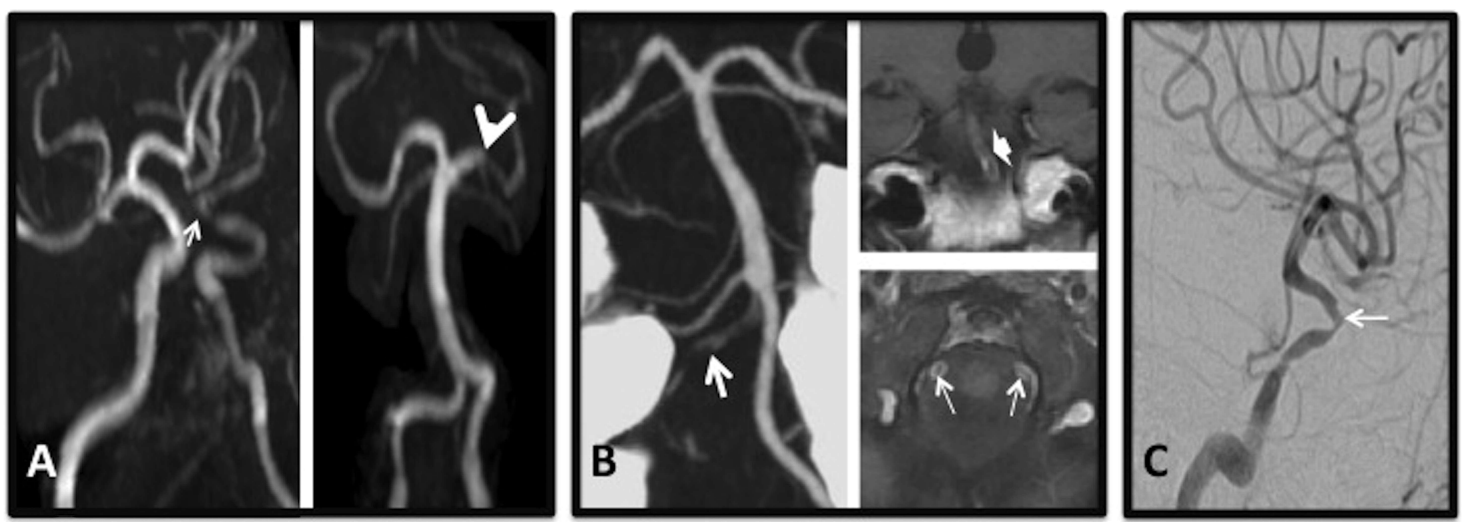

Figure 1. Imaging of intracranial vessels. A: Case 1. Maximum intensity projections of flow-sensitive magnetic resonance angiography show severe stenosis at the supraclinoid left internal carotid artery (thin white arrow) and irregularity of the left posterior cerebral artery (white arrowhead). B: Case 2. Computed tomography angiogram shows near occlusion of the right intradural vertebral artery (left). Post-contrast MRI shows abnormal mural enhancement of the basilar artery (top right) and vertebral arteries bilaterally (bottom right). C: Case 3. Digital subtraction angiogram shows severe narrowing at the anterior genu of the left internal carotid artery.

Personal non-commercial use only. The Journal of Rheumatology Copyright $@$ 2016. All rights reserved 


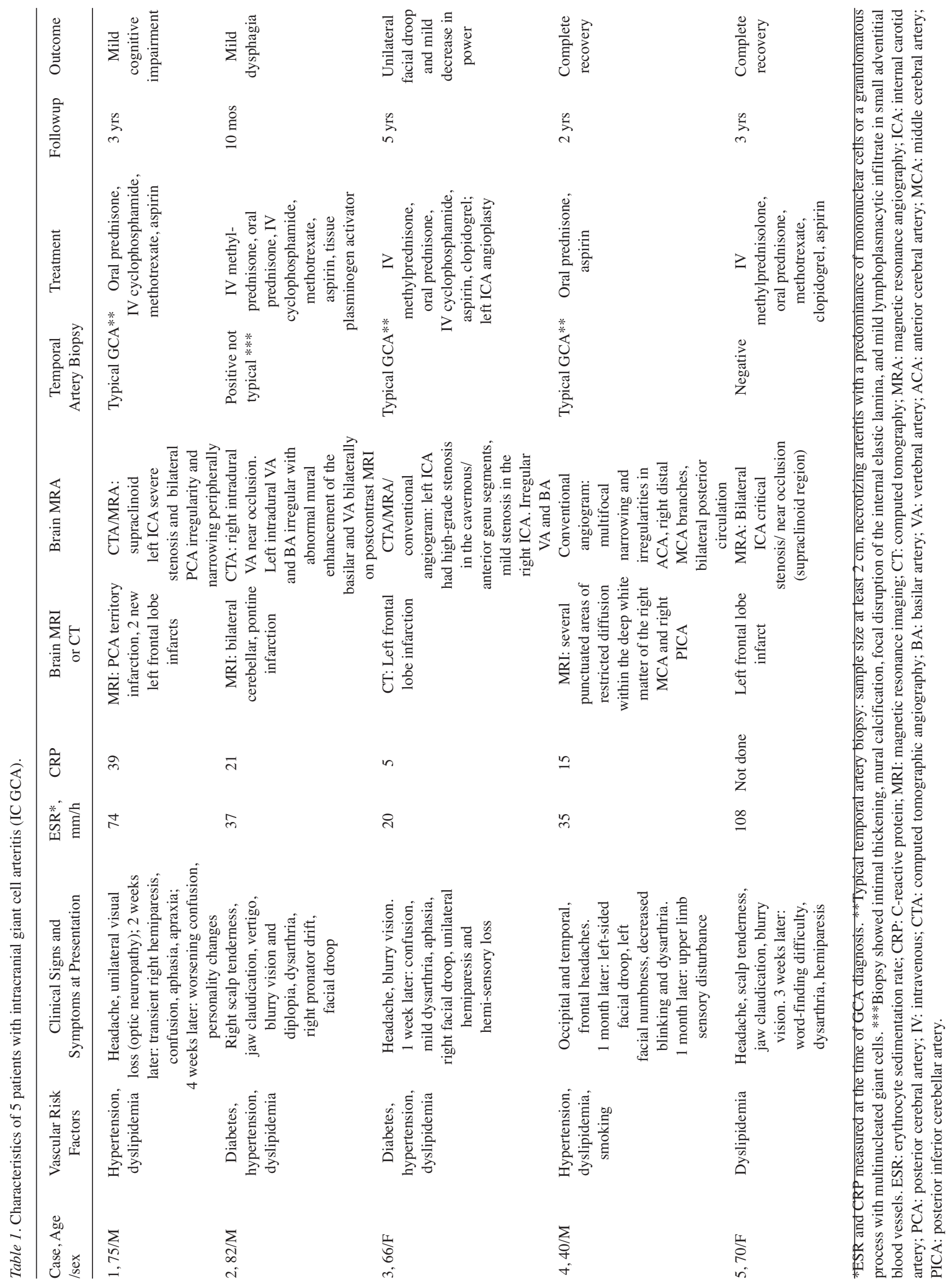

Personal non-commercial use only. The Journal of Rheumatology Copyright @ 2016. All rights reserved. 
started intravenous (IV) cyclophosphamide (CYC) $1 \mathrm{~g}$ monthly for 6 doses followed by subcutaneous (SC) methotrexate (MTX) $25 \mathrm{mg} /$ week. His prednisone was continued at $80 \mathrm{mg}$ daily, then gradually tapered to $5 \mathrm{mg}$ daily over a 5-month period. Over the 3-year followup, his cognition and weakness improved. He has not developed any new deficits or strokes. MRA performed 1 year after diagnosis did not show any disease progression.

Case 2. An 82-year-old man with polymyalgia rheumatica presented with a 2-week history of right scalp tenderness, jaw claudication, vertigo, blurry vision, and diplopia. Subsequently he had dysarthria, right-side arm weakness, and a facial droop. He was treated acutely with IV tissue plasminogen activator. He had scattered cerebellar infarcts and left pontine infarct on cerebral MRI. CTA showed caliber irregularities along the cervical vertebral arteries bilaterally. The intradural right vertebral artery was almost occluded, while the left intradural vertebral artery and basilar artery were irregular in caliber. There was abnormal mural enhancement of both the intradural vertebral artery and the basilar artery (Figure 1B). He was treated with IV methylprednisolone 1 $\mathrm{g}$ /day for 3 days followed by prednisone $70 \mathrm{mg} /$ day. He was given IV CYC $1 \mathrm{~g}$ monthly for 7 doses, followed by MTX $25 \mathrm{mg} /$ week SC for maintenance. His prednisone was tapered to $5 \mathrm{mg}$ daily. ASA was continued. He recovered completely except for some mild dysphagia and is doing well 10 months after his initial presentation. MRA performed 1 year after diagnosis did not show any disease progression.

Case 3. A 66-year-old woman with GCA who was treated with prednisone $80 \mathrm{mg} /$ day developed symptoms of confusion, aphasia, mild dysarthria, right facial droop, right-side weakness, and sensory impairment during 1 week when the prednisone was diminished to $40 \mathrm{mg} / \mathrm{day}$. CT of the head showed new infarcts in the left frontal lobe. Cerebral CTA and MRA showed a high-grade stenosis in the left ICA in the cavernous/anterior genu segments, mild stenosis in the right ICA, and vessel irregularity in the distal branches of the external carotid artery. The intracranial and extracranial vertebral arteries were small and irregular as was the basilar artery. Findings were further confirmed with conventional angiography (Figure 1). The patient was treated with ASA and IV methylprednisolone $1 \mathrm{~g}$ daily for 3 days, followed by oral prednisone $70 \mathrm{mg}$ /day and IV CYC $1 \mathrm{~g}$ monthly for 6 doses. She also had a left cavernous ICA angioplasty because of progressive worsening of the stenosis over time. Clopidogrel $75 \mathrm{mg}$ daily was added. Five years later, she has mild right facial droop and mild decrease in power on the right side and has not had any recurrent strokes. MRA performed 1 year after diagnosis did not show any disease progression. Case 4. A 40-year-old man presented with bilateral occipital headaches ${ }^{10}$. A month later he presented with left-side facial droop, left facial numbness, decreased blinking, and dysarthria. He was diagnosed with Bell's palsy and was treated with prednisone $40 \mathrm{mg} /$ day for 5 days and ASA. His facial palsy resolved but headache continued. A month later he developed left upper limb sensory disturbance. Lumbar puncture revealed inflammatory cerebrospinal fluid. A brain MRI showed several punctate areas of restricted diffusion within the deep white matter of the right MCA and right posterior inferior cerebellar artery territories. Conventional cerebral angiogram showed diffuse areas of multifocal narrowing and irregularities within the right anterior cerebral artery (ACA) and distal MCA branches; milder irregularities were found in the left ACA and bilateral posterior circulation vessels. A temporal artery biopsy was performed and was consistent with GCA. Prednisone $80 \mathrm{mg}$ daily was initiated with complete resolution of symptoms. He continued to do well with gradual prednisone taper and did not develop recurrent neurologic symptoms over 2 years of followup.

Case 5. A 70-year-old woman with new-onset GCA, treated with prednisone $50 \mathrm{mg}$ daily and ASA, developed word-finding difficulty, dysarthria, and right hemiparesis 3 weeks later. MRI of the head revealed an acute ischemic infarct in the left frontal lobe, and bilateral critical stenosis or near-occlusion of the terminal portion of both ICA in the supraclinoid region, with some milder stenosis within the petrous segments of both ICA. This stenosis was in relative isolation with no other changes of significant atherosclerosis within the ICA bulbs, proximal vessels, or aortic arch. She was treated with clopidogrel $75 \mathrm{mg}$ daily, IV methylprednisolone $1 \mathrm{~g}$ daily for 5 days, followed by prednisone $50 \mathrm{mg}$ and MTX $25 \mathrm{mg}$ orally weekly. Three years later she is still in complete remission, taking MTX and prednisone.

Literature review. Search results are shown in Figure 2; 28 articles and 42 cases met our inclusion criteria ${ }^{3,4,7,8,11-34}$. In our analysis we also included our 5 cases for a total of 47 cases with IC GCA. Our cases had characteristics similar to those found in the literature. We had 1 patient who was under 50 years of age; however, this patient had a temporal artery biopsy consistent with $\mathrm{GCA}^{10}$.

Demographics and clinical features of IC GCA cases. Forty-five cases (96\%) were over age 50 years and the mean age at the time of neurologic symptoms was 71 years. There were 19 women $(42 \%)$. Data on cardiovascular risk factors (diabetes, hypertension, hyperlipidemia, obesity, and smoking) were available for 22 cases (47\%). Of those, 10 $(45 \%)$ had 1 risk factor, $8(36 \%)$ had 2 or more risk factors, and $4(18 \%)$ had no risk factors.

The majority of cases $(30 / 47 ; 64 \%)$ developed CVA after GCA symptoms or diagnosis. The median time until CVA was 60 days (range 7 to 6205). Eight (17\%) developed CVA at the same time they presented with GCA symptoms. Nine (19\%) had no GCA symptoms at any point during the disease course, but met ACR criteria by having a positive temporal artery biopsy (7 cases) or a positive histopathology of temporal artery postmortem (1 case).

Table 2 summarizes the clinical features of the 47 cases.

Personal non-commercial use only. The Journal of Rheumatology Copyright @ 2016 . All rights reserved. 


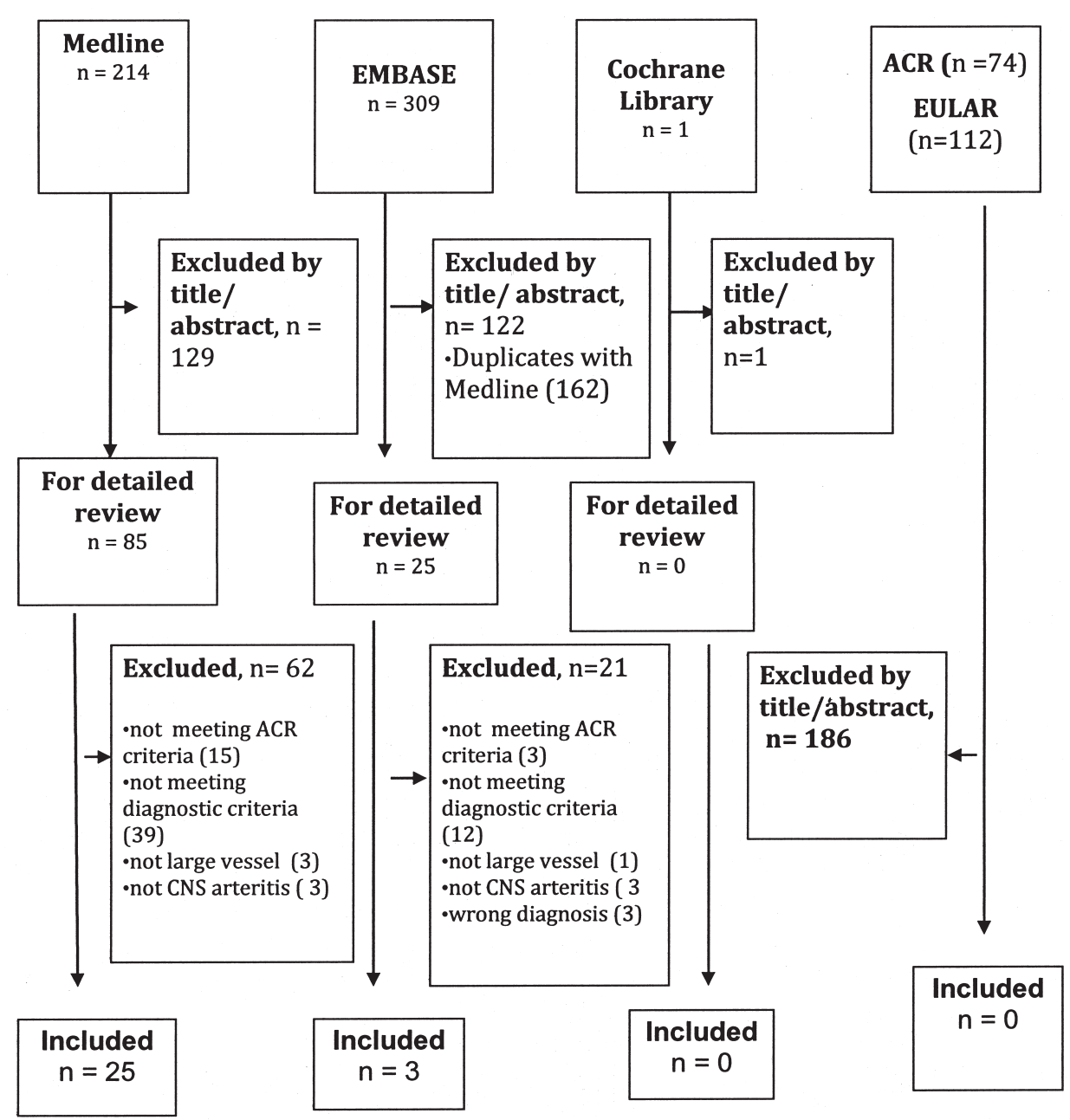

Figure 2. Literature search results. "Not meeting diagnostic criteria": cranial vasculitis not proven on magnetic resonance angiography, computed tomography angiography, or autopsy. ACR: American College of Rheumatology; EULAR: European League Against Rheumatism; CNS: central nervous system.

As expected, the most common GCA symptom was headache, in 34 cases (72\%). A high proportion (26\%) experienced unilateral blindness. Only 30 cases $(64 \%)$ had an elevated ESR at the time of diagnosis. The most common neurologic manifestations were cerebellar (34 cases; 72\%), motor impairment (29 cases; 62\%), and altered level of consciousness (23 cases; $49 \%$ ).

Treatment and outcomes of patients with IC GCA. Drug therapies used in the IC GCA cases are summarized in Table 3. Twenty-nine cases were not receiving corticosteroid at the time of stroke. Of these, 8 had stroke as the presenting feature of GCA, 8 had no classic GCA symptoms, 12 had a missed diagnosis of GCA, and 1 could not tolerate prednisone. Three cases had been tapered to doses of prednisone below $10 \mathrm{mg}$ daily at the time of stroke. Ten cases received an immunosuppressive agent in addition to high-dose corticosteroids; of these, 1 had angioplasty. Another case had angioplasty in addition to corticosteroids. Three out of 45 cases were receiving ASA prior to stroke. After the diagnosis of stroke, 10 were started on ASA, 6 on clopidogrel, and 12 on anticoagulation. Twenty-seven cases (57\%) were not reported to be receiving any antiplatelet or anticoagulant agents.

The overall mortality was high $(24 / 45 ; 53 \%)$. Of the survivors, 10 cases $(22 \%)$ had complete neurologic recovery. The cause of death was attributable to complications of IC GCA in most cases; 4 cases (9\%) died from infectious complications. Mortality was $60 \%(10 / 17)$ when vertebrobasilar arteries were involved and $81 \%$ (9/11) for extradural disease compared to $48 \%$ (16/33) for intradural disease. Mortality in the cases not treated with corticosteroids or who were receiving prednisone doses below $10 \mathrm{mg}$ daily at the time of stroke was similar to those receiving higher doses of corticosteroids ( $56 \%$ vs $50 \%$, respectively). Two cases were not receiving any treatment throughout the course of their disease and both died from cerebrovascular complications. Cases treated with an immunosuppressive agent in 
Table 2. Clinical features of IC GCA and distribution of affected vessels $(\mathrm{n}=47)$.

\begin{tabular}{lc}
\hline Clinical features & $\mathrm{n}(\%)$ \\
\hline GCA symptoms & \\
Headache & $34(72)$ \\
Systemic symptoms* & $24(51)$ \\
Temporal artery abnormalities/scalp tenderness & $19(40)$ \\
Nonsevere visual symptoms** & $18(38)$ \\
Unilateral blindness & $12(26)$ \\
Jaw claudication & $11(23)$ \\
PMR & $10(21)$ \\
Neurologic symptoms & \\
Cerebellar & \\
Motor & $34(72)$ \\
Altered LOC/coma & $29(62)$ \\
Cranial nerves & $23(49)$ \\
Cognitive/memory decline & $19(40)$ \\
Speech & $12(26)$ \\
Sensory & $10(21)$ \\
Timing of neurologic symptom in relation to GCA symptoms \\
Same time as GCA symptoms & $10(21)$ \\
No GCA symptoms & $8(17)$ \\
After GCA symptoms & $9(19)$ \\
Disease distribution & \\
Territory involved & $30(64)$ \\
Vertebrobasilar territory & \\
Carotid territory & \\
Both territories & \\
Location with respect to dura & $17(36)$ \\
Intradural & $6(13)$ \\
Extradural & $24(51)$ \\
Unknown & \\
\hline
\end{tabular}

*Systemic symptoms include anorexia/weight loss, fever, fatigue, and myalgia. **Visual symptoms include blurry vision and eye pain. ${ }^{\dagger}$ Gait ataxia: 20 (59), dysarthria: 17 (50), diplopia: 10 (29), vertigo: 9 (26), nystagmus: 7 (21), incoordination: 6 (18). ${ }^{\ddagger}$ Determined using the following: MR angiogram: 18 (38), autopsy: 14 (30), conventional angiography: 13 (28), or CT angiogram: 2 (4). IC GCA: intracranial giant cell arteritis; PMR: polymyalgia rheumatica; LOC: level of consciousness.

addition to corticosteroids had lower mortality, 4 out of 10 $(40 \%)$ versus 18 out of $31(58 \%)$ in the cases treated with corticosteroids only. Four of 8 cases treated with CYC died: 1 from pneumonia, 1 from line sepsis post-angioplasty, and 2 died shortly after presentation from severe stroke complications.

\section{DISCUSSION}

We describe a total of 47 GCA cases (5 new) with IC involvement. Cerebral vascular events occurred after the diagnosis of GCA in $64 \%$, with a median duration of 60 days. A large proportion of cases were not receiving prednisone $(64 \%)$ or aspirin $(93 \%)$ at the time of CVA. Significant morbidity and mortality was associated with IC GCA: mortality was $53 \%$ with a median time to death of 12 days; of the cases who survived, $24 \%$ had residual neurologic deficits.

Given the significant complications associated with IC
GCA, it is important to identify these patients early. There are no published studies that investigate predictors for intracranial vasculitis in patients with GCA. We found that in IC GCA, the proportion of males (58\%) and prevalence of blindness $(26 \%)$ was higher, and the prevalence of polymyalgia rheumatica and jaw claudication was lower $(21 \%$ and $23 \%$, respectively) than previously reported for $\mathrm{GCA}^{2,35,36}$. However, we cannot make any conclusions regarding screening, especially because the incidence of IC GCA is unknown. CVA in GCA is reported to occur in $4 \%-6 \% 2$, but the proportion attributable to IC vasculitis versus atherosclerosis remains unclear. The presence of active GCA symptoms at the time of CVA may suggest IC vasculitis. However, we found that $19 \%$ of cases did not have any GCA symptoms before or at the time of CVA, and upon autopsy some of these cases were shown to have active IC arteritis.

We also observed that IC GCA commonly presented with multiterritory CVA, with a predilection for vertebrobasilar arteries. This can be distinguished from atherosclerotic disease, which more commonly affects the middle cerebral $\operatorname{arteries}^{4,37}$.

The diagnosis of IC GCA is also limited by the available imaging modalities. Although conventional angiography is the most sensitive, it is not specific for vasculitis, particularly in patients with concomitant atherosclerotic disease. Findings that support vasculitis include alternating areas of stenosis and dilatation in the second- and third-order arterial branches and venous territories; and less commonly, long-segment stenosis and pseudoaneurysms ${ }^{38}$. CTA and MRA evaluate the vessel wall and lumen ${ }^{39}$. However, specific signs of vasculitis (vessel wall edema, mural contrast enhancement, and circumferential vessel wall thickness) may not be detected in smaller vessels, especially when not using 3-T MRI ${ }^{18}$. Positron emission tomography has been shown to be more sensitive than $\mathrm{MRI}^{40}$, but it is not widely available, provides limited anatomical visualization, and may be falsely positive in acute atherosclerotic vascular disease ${ }^{41}$.

If IC GCA is suspected, there are no controlled or observational studies to guide treatment decisions. We found lower mortality in patients who started receiving immunosuppressive agents in conjunction with corticosteroids compared to those who received corticosteroids alone (40\% vs $58 \%$, respectively). Prednisone and methylprednisone inefficiently cross the blood-brain barrier, which may make treating central nervous system vasculitis with these agents difficult; this raises the question whether dexamethasone should be used $^{42}$. However, only one of the reported cases used dexamethasone, so there is insufficient information to comment on its effectiveness in treating IC GCA compared to other corticosteroids. Several studies examined using immunosuppressive agents in conjunction with corticosteroids in $\mathrm{GCA}^{43,44,45}$. In a metaanalysis, MTX was shown to be better than placebo in preventing relapse of GCA. It is also an

Personal non-commercial use only. The Journal of Rheumatology Copyright $\odot$ 2016. All rights reserved. 
Table 3. Treatments and outcomes of IC GCA cases $(\mathrm{n}=45)$.

\begin{tabular}{|c|c|c|c|c|c|c|}
\hline & \multirow[t]{2}{*}{$\mathrm{N}(\%)$} & \multirow{2}{*}{$\begin{array}{l}\text { Followup, Median } \\
\text { No. Mos (range) }\end{array}$} & \multicolumn{2}{|c|}{ Recovery } & \multirow[t]{2}{*}{ Death, n (\%) } & \multirow{2}{*}{$\begin{array}{l}\text { Time to Death } \\
\text { Median No. } \\
\text { Days (range) }\end{array}$} \\
\hline & & & $\mathrm{CR}, \mathrm{n}(\%)$ & $\mathrm{PR}, \mathrm{n}(\%)$ & & \\
\hline Corticosteroids alone & $31(69)$ & $3(1-85)$ & $6(19)$ & $7(23)$ & $18(58)$ & $10(1-120)$ \\
\hline Corticosteroids and methotrexate or azathioprine & $2(4)$ & $35(\mathrm{NR})$ & $2(100)$ & 0 & 0 & NA \\
\hline Steroids and CYC & $3(7)$ & NA & NA & NA & $3(100)$ & $160(12-540)$ \\
\hline Corticosteroids, methotrexate, and CYC & $2(4)$ & $23(10-36)$ & 2 & $2(100)$ & 0 & NA \\
\hline Corticosteroids, angioplasty, and CYC & $3(7)$ & $13(1-24)$ & 0 & $2(67)$ & $1(33)$ & 210 \\
\hline Corticosteroids and angioplasty & $1(2)$ & 48 & $1(100)$ & 0 & 0 & NA \\
\hline Corticosteroids and surgery* & $1(2)$ & NR & $1(100)$ & 0 & 0 & NA \\
\hline No treatment & $2(4)$ & NA & NA & NA & $2(100)$ & $3.5(2-5)$ \\
\hline Total & 45 & $5(1-85)$ & $10(22)$ & $11(24)$ & $24(53)$ & $12(1-540)$ \\
\hline
\end{tabular}

*Superficial temporary artery to MCA bypass. Initial corticosteroids: oral prednisone ( $\mathrm{n}=27$; mean dose $60 \mathrm{mg}$ for $2-3$ weeks), IV methylprednisone $1 \mathrm{~g}$ daily for $\leq 3$ days $(\mathrm{n}=7$ ), IV methylprednisone $1 \mathrm{~g}$ daily for $\geq 5$ days (3), IV methylprednisone $1 \mathrm{~g}$ daily for unknown duration $(\mathrm{n}=3)$, other corticosteroids $(\mathrm{n}=3$ ). Note: treatment and outcome was not reported in 2 patients. CR: complete recovery from neurologic deficits; PR: partial recovery; IC GCA: intracranial giant cell arteritis; NA: not applicable; NR: not reported; MCA: middle cerebral artery; IV: intravenous; CYC: cyclophosphamide.

effective steroid-sparing agent ${ }^{45}$. CYC has also shown potential benefit as a corticosteroid-sparing agent in patients with $\mathrm{GCA}^{43}$, and there is evidence supporting its use in primary angiitis of the central nervous system ${ }^{46}$.

Given that a large proportion of IC GCA cases had at least 1 risk factor for atherosclerotic disease $(>80 \%)$, and that GCA bears an increased risk of cardiovascular events ${ }^{47}$ and possible worsening of preexisting cardiovascular comorbidities by corticosteroids, the management of modifiable cardiovascular risk factors in GCA is critical. Unfortunately, the majority of the articles included in this review did not report how cardiovascular risk factors were managed. Based on 2 recently published metaanalyses, antiplatelet therapy appears to be beneficial in subjects with $\mathrm{GCA}^{48,49}$. Only $57 \%$ of the reported IC GCA cases were started on an antiplatelet or anticoagulant therapy although they all experienced a CVA.

Our study has several strengths: we carefully characterized vascular risk factors, imaging findings, treatment, and outcomes. Our newly reported cases were managed in an interdisciplinary clinic (rheumatology, neurology, ophthalmology, pathology, and neuroradiology); several imaging modalities were used to confirm diagnosis of IC GCA and atherosclerotic CVA was ruled out. The cases had very good neurological outcomes. The presentation and clinical outcomes of our cases were similar to those in a recent series that described 4 cases of IC GCA that were also treated aggressively with combinations of corticosteroids and immunosuppressants ${ }^{50}$. From the literature review, the mortality of IC GCA may be an overestimate, because severe cases tend to be more commonly reported. Alternatively, underreporting might also be a problem: CVA secondary to GCA might be misdiagnosed because of the lack of classic GCA symptoms, or CVA in patients with GCA may be wrongly attributed to atherosclerotic disease.

IC GCA is a serious condition and may be associated with neurologic complications and mortality. When GCA is diagnosed, physicians should maintain a high index of suspicion for intracranial involvement, particularly in patients with neurologic symptoms and vision loss. If IC GCA is suspected, imaging should be performed to confirm intracranial vasculitis and to distinguish it from atherosclerotic disease. Controlled drug studies for IC GCA are lacking. However, it can be treated like complicated GCA following current published guidelines with IV methylprednisolone followed by $1 \mathrm{mg} / \mathrm{kg}$ prednisone. Alternatively, dexamethasone may be a better corticosteroid option for IC GCA, as it crosses the blood-brain barrier more efficiently ${ }^{42}$. Concomitant cardiovascular risk factors are common in IC GCA and must be managed. Antiplatelet therapy should be considered for all patients with GCA and should be initiated in patients with arterial thromboembolic events without contraindications. We found that in some cases corticosteroid alone was not sufficient to prevent neurologic complications; it may be necessary to add other immunosuppressive agents, such as MTX or CYC depending on the severity of the disease. Larger studies are needed to better characterize IC GCA, determine optimal treatment, and improve outcomes.

\section{ACKNOWLEDGMENT}

The authors acknowledge CanVasc members Simon Carette, Rae Yeung, Nataliya Milman, Tanveer Towheed, Leilani Famorca, Carter Thorne, Patrick Liang, Michelle Goulet, Christian Pineau, Judith Trudeau, Paul Fortin, Volodko Bakowsky, Christine Dipchand, Kam Shojania, David Cabral, Elaine Yacyshyn, Aurore Fifi-Mah, Susan Benseler, Navjot Dhindsa, Regina Taylor-Gjevre, and Majed Khraishi. The authors also thank Brad Dishan, Medical Librarian, for assisting in the literature search.

\section{REFERENCES}

1. Lawrence RC, Felson DT, Helmick CG, Arnold LM, Choi H, Deyo RA, et al. Estimates of the prevalence of arthritis and other rheumatic conditions in the United States. Part II. Arthritis Rheum 2008;58:26-35. 
2. Gonzalez-Gay MA, Barros S, Lopez-Diaz MJ, Garcia-Porrua C, Sanchez-Andrade A, Llorca J. Giant cell arteritis: disease patterns of clinical presentation in a series of 240 patients. Medicine 2005;84:269-76

3. Save-Soderbergh J, Malmvall BE, Andersson R, Bengtsson BA. Giant cell arteritis as a cause of death. Report of nine cases. JAMA 1986;255:493-6.

4. Wilkinson IM, Russell RW. Arteries of the head and neck in giant cell arteritis. A pathological study to show the pattern of arterial involvement. Arch Neurol 1972;27:378-91.

5. Bogousslavsky J, Deruaz JP, Regli F. Bilateral obstruction of internal carotid artery from giant-cell arteritis and massive infarction limited to the vertebrobasilar area. Eur Neurol 1985;24:57-61.

6. Cardell BS, Hanley T. A fatal case of giant-cell or temporal arteritis. J Pathol Bacteriol 1951;63:587-97.

7. Sheehan MM, Keohane C, Twomey C. Fatal vertebral giant cell arteritis. J Clin Pathol 1993;46:1129-31.

8. Thielen KR, Wijdicks EF, Nichols DA. Giant cell (temporal) arteritis: involvement of the vertebral and internal carotid arteries Mayo Clin Proc 1998;73:444-6.

9. Hunder GG, Bloch DA, Michel BA, Stevens MB, Arend WP, Calabrese LH, et al. The American College of Rheumatology 1990 criteria for the classification of giant cell arteritis. Arthritis Rheum 1990;33:1122-8.

10. McGeoch L, Silecky WB, Maher J, Carette S, Pagnoux C. Temporal arteritis in the young. Joint Bone Spine 2013;80:324-7.

11. Ahdab R, Thabuy F, Menager de Froberville E, Brugieres P, Hosseini $\mathrm{H}$. Reversible vertebral artery stenosis following corticotherapy in giant cell arteritis. Eur Neurol 2008;59:331 .

12. Akdal G, Thurtell MJ, Halmagyi GM. Giant cell arteritis presenting with bilateral vertebral and axillary artery occlusions. Intern Med J 2008;38:741-2.

13. Buttner T, Heye N, Przuntek H. Temporal arteritis with cerebral complications: report of four cases. Eur Neurol 1994;34:162-7.

14. Chowdhary V, Kallmes DF, Fulgham J, Meyer F, Matteson EL. Recurrent spells and bilateral internal carotid artery stenosis in a diabetic male: A test of patien-ce(-ts). Arthritis Rheum 2007;57:1098-101.

15. Dementovych N, Mishra R, Shah QA. Angioplasty and stent placement for complete occlusion of the vertebral artery secondary to giant cell arteritis. J Neurointerv Surg 2012;4:110-3.

16. Ely GM. Giant cell arteritis complicated by multi-infarct dementia. J Clin Rheumatol 1998;4:209-15.

17. Galetta SL, Balcer LJ, Liu GT. Giant cell arteritis with unusual flow-related neuro-ophthalmologic manifestations. Neurology 1997;49:1463-5

18. Geiger J, Uhl M, Peter HH, Langer M, Bley TA. 3-T MRI detects inflammatory stenosis of the vertebral artery in giant cell arteritis. Clin Rheumatol 2008;27:663-6.

19. Gibb WR, Urry PA, Lees AJ. Giant cell arteritis with spinal cord infarction and basilar artery thrombosis. J Neurol Neurosurg Psychiatry 1985;48:945-8.

20. Kjeldsen MH, Reske-Nielsen E. Pathological changes of the central nervous system in giant-cell arteritis. Acta Ophthalmol 1968; 46:49-56.

21. Lempel J, Bernstein S, Kalina P. Infarction of the corpus callosum: a manifestation of giant cell arteritis. AJNR Am J Neuroradiol 2011;32:E182-3

22. Lu-Emerson C, Walker M, Huber BR, Ghodke B, Longstreth WT Jr, Khot SP. Lethal giant cell arteritis with multiple ischemic strokes despite aggressive immunosuppressive therapy J Neurol Sci 2010;295:120-4

23. McLean CA, Gonzales MF, Dowling JP. Systemic giant cell arteritis and cerebellar infarction. Stroke 1993;24:899-902.
24. Ronthal M, Gonzalez RG, Smith RN, Frosch MP. Case records of the Massachusetts General Hospital. Weekly clinicopathological exercises. Case 21-2003. A 72-year-old man with repetitive strokes in the posterior circulation. N Engl J Med 2003;349:170-80.

25. Ruegg S, Engelter S, Jeanneret C, Hetzel A, Probst A, Steck AJ, et al. Bilateral vertebral artery occlusion resulting from giant cell arteritis: report of 3 cases and review of the literature. Medicine $2003 ; 82: 1-12$

26. Salvarani C, Giannini C, Miller DV, Hunder G. Giant cell arteritis: involvement of intracranial arteries. Arthritis Rheum 2006;55:985-9.

27. Semmler A, Urbach H, Klockgether T. Giant cell arteritis causing multiple vertebro-basilar infarcts. Neurology 2002;58:1399.

28. Solans-Laque R, Bosch-Gil JA, Molina-Catenario CA, Ortega-Aznar A, Alvarez-Sabin J, Vilardell-Tarres M. Stroke and multi-infarct dementia as presenting symptoms of giant cell arteritis: report of 7 cases and review of the literature. Medicine 2008;87:335-44.

29. Stark CD, Hughes A. Atypical temporal arteritis causing posterior circulation stroke. J Clin Neurosci 2010;17:1206-7.

30. Thomson GT, Johnston JL, Sharpe JA, Inman RD. Internuclear ophthalmoplegia in giant cell arteritis. J Rheumatol 1989;16:693-5.

31. Thystrup J, Knudsen GM, Mogensen AM, Fledelius HC. Atypical visual loss in giant cell arteritis. Acta Ophthalmol 1994;72:759-64.

32. Topakian R, Stieglbauer K, Nussbaumer K, Dreer B, Sonnberger M, Aichner FT. Reversibility of basilar artery stenosis following timely treatment of temporal arteritis. Cerebrovasc Dis 2009;27:204-6.

33. Wiszniewska M, Devuyst G, Bogousslavsky J. Giant cell arteritis as a cause of first-ever stroke. Cerebrovasc Dis 2007;24:226-30.

34. Zwicker J, Atkins EJ, Lum C, Sharma M. An atypical presentation of giant cell arteritis. CMAJ 2011;183:E301-5.

35. Gonzalez-Gay MA, Garcia-Porrua C, Llorca J, Hajeer AH, Branas F, Dababneh A, et al. Visual manifestations of giant cell arteritis. Trends and clinical spectrum in 161 patients. Medicine 2000;79:283-92.

36. Salvarani C, Hunder GG. Musculoskeletal manifestations in a population-based cohort of patients with giant cell arteritis. Arthritis Rheum 1999;42:1259-66.

37. Turney TM, Garraway WM, Whisnant JP. The natural history of hemispheric and brainstem infarction in Rochester, Minnesota. Stroke 1984;15:790-4.

38. Calabrese LH, Duna GF, Lie JT. Vasculitis in the central nervous system. Arthritis Rheum 1997;40:1189-201.

39. Gotway MB, Araoz PA, Macedo TA, Stanson AW, Higgins CB, Ring EJ, et al. Imaging findings in Takayasu's arteritis. AJR Am J Roentgenol 2005;184:1945-50.

40. Belhocine T, Blockmans D, Hustinx R, Vandevivere J, Mortelmans L. Imaging of large vessel vasculitis with (18)FDG PET: illusion or reality? A critical review of the literature data. Eur J Nucl Med Mol Imaging 2003;30:1305-13.

41. Yun M, Yeh D, Araujo LI, Jang S, Newberg A, Alavi A. F-18 FDG uptake in the large arteries: a new observation. Clin Nucl Med 2001;26:314-9.

42. Balis FM, Lester CM, Chrousos GP, Heideman RL, Poplack DG. Differences in cerebrospinal fluid penetration of corticosteroids: possible relationship to the prevention of meningeal leukemia. J Clin Oncol 1987;5:202-7.

43. de Boysson H, Boutemy J, Creveuil C, Ollivier Y, Letellier P, Pagnoux $\mathrm{C}$, et al. Is there a place for cyclophosphamide in the treatment of giant-cell arteritis? A case series and systematic review. Semin Arthritis Rheum 2013;43:105-12.

44. De Silva M, Hazleman BL. Azathioprine in giant cell arteritis/polymyalgia rheumatica: a double-blind study. Ann Rheum Dis 1986;45:136-8.

45. Mahr AD, Jover JA, Spiera RF, Hernandez-Garcia C, Fernandez-Gutierrez B, Lavalley MP, et al. Adjunctive methotrexate 
for treatment of giant cell arteritis: an individual patient data meta-analysis. Arthritis Rheum 2007;56:2789-97.

46. Langford CA. Management of systemic vasculitis. Best Pract Res Clin Rheumatol 2001;15:281-97.

47. Tomasson G, Peloquin C, Mohammad A, Love TJ, Zhang Y, Choi HK, et al. Risk for cardiovascular disease early and late after a diagnosis of giant-cell arteritis: a cohort study. Ann Intern Med 2014; $160: 73-80$

48. Martinez-Taboada VM, Lopez-Hoyos M, Narvaez J, Munoz-Cacho P. Effect of antiplatelet/anticoagulant therapy on severe ischemic complications in patients with giant cell arteritis: a cumulative meta-analysis. Autoimmun Rev 2014;13:788-94.

49. Jeong J, Barra L. The use of anti-platelet and/or anticoagulant agents in the prevention of large vessel vasculitis-associated ischemic complications: a meta-analysis. OJRA 2014;4:114-23.

50. Lariviere D, Sacre K, Klein I, Hyafil F, Choudat L, Chauveheid MP, et al. Extra- and intracranial cerebral vasculitis in giant cell arteritis: an observational study. Medicine 2014;93:e265

APPENDIX 1. Complete search strategy.

\section{EMBASE}

1. Keywords: Giant cell arteritis or GCA or temporal arteritis or Giant cell angiitis. EMTREE: Giant cell arteritis

2. Keywords: cerebrovascular accident or CVA or stroke or brain/ cerebral/ cerebellar/ cerebral artery infarct or transient ischemic attack or TIA or intracranial/cerebral AND thromb or dementia or internal carotid/ vertebral/ basilar/ vertebrobasilar AND occlusion/ stenosis/ insufficiency or posterior circulation or neurology

EMTREE: cerebrovascular disease or brain ischemia or transient ischemic attack or brain infarction/ brainstem infarction/ cerebellum infarction or occlusive cerebrovascular disease or basilar artery obstruction or middle cerebral artery occlusion or vertebral artery stenosis or cerebral artery disease or vertebrobasilar insufficiency or cerebrovascular accident or lacunar stroke or anterior cerebral artery/ middle cerebral artery/ posterior cerebral artery/ basilar artery/ anterior communicating artery/ posterior communicating artery/ posterior inferior cerebellar artery/ brain circulus arteriosus/ meningeal artery

Medline:

1. Keywords: Giant cell arteritis or GCA or temporal arteritis or Giant cell angiitis. MeSH: Giant cell arteritis 2. Keywords: cerebrovascular accident or CVA or stroke or brain/ cerebral/ cerebellar/ cerebral artery infarct or transient ischemic attack or TIA or intracranial/cerebral AND thromb or dementia or internal carotid/ vertebral/ basilar/ vertebrobasilar AND occlusion/ stenosis/ insufficiency or posterior circulation or neurology MeSH: cerebrovascular disorders or brain ischemia or brain infarction or ischemic attack, transient or vertebrobasilar insufficiency or cerebral small vessel disease, stroke, lacunar or dementia, vascular or dementia, multi-infarct or intracranial arterial disease or cerebral arterial disease or infarction (anterior, middle, posterior) cerebral artery or intracranial thrombosis or stroke or vasculitis, central nervous system Cochrane:

1. Keywords: Giant cell arteritis or GCA or temporal arteritis or Giant cell angiitis. MeSH: Giant cell arteritis 2. Keywords: cerebrovascular accident or CVA or stroke or brain/ cerebral/ cerebellar/ cerebral artery infarct or transient ischemic attack or TIA or intracranial/cerebral AND thromb or dementia or internal carotid/ vertebral/ basilar/ vertebrobasilar AND occlusion/ stenosis/ insufficiency or posterior circulation or neurology 